\title{
Symptoms and underlying diseases associated with the hospitalization period of 3480 Covid-19 patients in Hormozgan, Iran
}

\author{
Hesamuddin Kamalzadeh Takhti ${ }^{1}$, Mahdieh Ardaneh ${ }^{2}$, Shahram Zare ${ }^{3}$, Maryam Rezaei \\ Sarkhaei $^{4}$, Ehsan Amiri-Ardekani, ${ }^{5,6,7,8}$
}

1. Department of Social Medicine, School of Medicine, Hormozgan University of Medical Sciences, Iran

2. Epidemiology Department, School of Health, Shiraz University of Medical Sciences, Shiraz, Iran mahdiehardaneh73@gmail.com

3. Department of Social Medicine, Faculty of Medicine, Hormozgan University of Medical Sciences, Iran

4. Department of Statistics, Statistics Management and Information Technology, Hormozgan University of Medical Sciences, Iran, rezaei.sarkhaei@yahoo.com

5. Department of Phytopharmaceuticals (Traditional Pharmacy), Shiraz University of Medical Sciences, Shiraz, Iran

6. Student Research Committee, Shiraz University of Medical Sciences, Shiraz, Iran

7. Student Association of Indigenous Knowledge, Shiraz University of Medical Sciences, Shiraz, Iran

8. Research Center for Traditional Medicine and History of Medicine, Shiraz University of Medical Sciences, Shiraz, Iran 


\section{Abstract}

Introduction: COVID-19 has a relationship with patients' demographic characteristics as well as their underlying diseases. This research has been conducted to evaluate factors' effect on Covid-19 patient's hospitalization rate and period in Hormozgan, Iran.

Materials and Methods: The inclusion criteria of this retrospective study included all patients diagnosed as COVID-19 Patients after PCR who were referred to Covid-19 hospitals from February 2020 to June 2020 in Hormozgan province, Iran. After the completion of the consent form and observing ethical principles, 3480 patients' information was collected through the interview by Medical care monitoring center unit experts. The checklist was designed according to COVID-19 guidelines and approved by the World Health Organization and Iran Ministry of Health and Medical Education. The studied variables included gender, age, patients' residence place, smoking history and medications use history, pregnancy, referral type to hospital, contact history with COVID-19 patients, early symptoms, gastrointestinal symptoms, intubation, Po2 level, history of cancer, chronic liver diseases, diabetes, chronic blood diseases, HIV/AIDS, acquired or congenital immunodeficiency, cardiovascular diseases, chronic kidney diseases, dialysis status, asthma and other chronic lung diseases, and chronic neurological disorders. These data were analyzed using descriptive (average-standard deviation-percentage) and analytical (including Chi-square, ttest, and regression tests) statistics with SPSS Ver.23 software.

Results: In this study, 3480 COVID-19 patients including 1852 male patients (53.20\%) with a median age of $43.11 \pm 21.72$ and 1628 female patients $(46 / 80 \%)$ with a median age of $44.86 \pm 22.40$. The median age of men was 
significantly lower than the women's median age $(\mathrm{P}=0.02)$. The duration of hospitalization of male and female patients was reported 2.64 \pm 4.14 and 2.76 \pm 4.297 , respectively which was not statistically significant. The death rate of patients in our study was $6.6 \%$.

Conclusion: The results of this study also showed that the hospitalization period of HIV-positive patients and patients with cardiovascular and pulmonary diseases is much longer than other people, which imposes many human and financial costs on the country's health care system. Therefore, to maintain individual health and help improve the critical condition of the virus, it is better to develop and apply stricter protocols to prevent further outbreaks of the disease and check underlying diseases of people suspected to have Covid-19. These results can improve health care system planning and improving medical services presented to covid-19 patients.

Keywords: COVID-19, hospitalization period, respiratory disease, Hormozgan 


\section{Introduction}

In late December 2019, an unknown case of pneumonia was reported in Wuhan with similar clinical symptoms to viral pneumonia. The WHO introduced the virus as COVID-19. This virus is from the beta-corona genera of viruses that have different potential hosts $(1,2)$. Coronaviruses are single-stranded, enveloped, RNA viruses with 120-180 nm diameter. Before the COVID-19, there were only six coronaviruses that could infect humans. Among coronaviruses, four strains including OC43, 229E, HKU1, and NL63 have less pathogenicity and cause mild respiratory illness. However, two strains that are SARS-CoV and MERS-CoV have caused two fatal epidemics. The homology and pathogenesis mechanism of COVID-19 is very similar to the SARS-CoV pathogenesis mechanism. Due to the adaptation of COVID-19 to bats' bodies and higher temperature of their body in comparison with the human's body, this virus has become more stable than SARS-CoV $(3,4)$.

Genetic diversity and frequent mutations of the virus has increased its transmission (5). The natural hosts of the virus are the bats and penguins and snakes act as intermediate hosts. The most common way of transmission in a community is direct contact and respiratory droplets. Its incubation period averages 3 days (ranging from 0 to 24 days) and the average time from the onset of the first symptoms to death is 14 days $(6,7)$. While asymptomatic carriers play an important role in the person-to-person transmission, there is limited information on them. People under the age of 15 make up a significant proportion of these carriers. Clinical signs and CT scans do little to help diagnose asymptomatic carriers and as most of them have no clinical symptoms and normal CT scans, so the best way to diagnose carriers is the Real-Time PCR test(8). 
Based on recent studies, there is a correlation between COVID-19 and demographic characteristics. The highest mortality rate is related to elderly men at the age of 65 years or older (9) with underlying diseases such as diabetes, high blood pressure, chronic respiratory disease, and cancer, high interleukin-6 level, or a history of previous surgery. The cellular immune system function-which is an important feature of the immune system against viral infections- decreases in the elderly. $(1,6,10-12)$.

The most common clinical symptoms of COVID-19 infection are Fever (87.9\%), cough (67.7\%), fatigue (38.1\%). vomiting (5\%) and diarrhea (3.7\%) (7). Also, confusion, forgetfulness, olfactory dysfunction, neuropathic pain, seizure, and stroke are among the neurological symptoms of this virus that result in hypoxia and inflammation of the brain. Brain inflammation can be indirectly caused by a cytokine storm (autoimmune encephalitis) or directly caused by a broken blood-brain barrier by a virus (viral encephalitis) $(13,14)$. Besides, Acute Respiratory Distress Syndrome (ARDS) occurs around 90 days after infection. The virus also damages other tissues, including the heart, kidneys, liver, eyes, and nervous systems too (7).

Having a healthy lifestyle, including exercise, good nutrition, a balanced weight, and non-smoking contribute to a balanced immune system and Covid-19 prevention. Based on recent findings, the most prominent reason for the morbidity and mortality rate caused by Covid-19 in the US is overweight $(15,16)$. Also, personal hygiene, using the face mask, adequate rest, and proper ventilation are among effective ways to prevent infection(1).

Disease occurrence depends on the interaction between the virus and the immune system. Virus-related factors also include the type of virus, mutation, and the number of viruses. A person's immune system is also affected by genetics (e.g. HLA gene), age, gender, nutritional status, homeostasis between the immune, nervous and endocrine systems, and physical condition. All of these 
factors contribute to an individual's infection, the duration and severity, and the recurrence of the disease. Since the exact mechanism of transmission of the disease is not fully understood and vaccines don't make permanent protection, the most important task now is to interrupt the chain of transmission (16). Therefore, this study was conducted in 2020, in the Hormozgan province, to analyze symptoms and factors affecting the duration of hospitalization in COVID-19 patients.

\section{Materials and Methods}

This study was conducted from January 21, 2020, to May 30, 2020, in Hormozgan province to analyze the hospitalization period of COVID-19 patients. The research participants of this study were all patients that were referred to hospitals in Hormozgan province with a diagnosis of COVID-19 based on a PCR test.

Inclusion criteria were patients diagnosed with COVID-19 after a Realtime PCR test. Exclusion criteria were patients who did not consent to participate in this study or had incomplete or distorted information. Based on these inclusion and exclusion criteria, 3480 patients were included in the study.

Patients' information has been collected through the interview by MCMC (Medical care monitoring center) personnel in the hospitals after the completion of the consent form and observing ethical principles. The checklist used to collect information has been designed according to Iran national COVID-19 guidelines and approved by the Iran Ministry of Health and Medical Education as well as the World Health Organization. The studied variables were gender, age, patients' resident place, history of smoking and drug use, pregnancy, referral type to the hospital (by or without an ambulance), history of contact with COVID-19 patients, early symptoms (including cough, muscular pain, level of consciousness, respiratory, olfactory and taste dysfunction, seizure, headache, 
dizziness, paresis and limb palsy, chest pain, inflammation and skin lesions, stomach ache, nausea, vomiting, diarrhea, and anorexia), intubation, Po2 level, history of cancer, chronic liver diseases, diabetes, chronic blood diseases, HIV/AIDS, acquired or congenital immunodeficiency, cardiovascular diseases, chronic kidney diseases and dialysis status, asthma and other chronic lung diseases and chronic neurological disorders. These data were entered into SPSS V.23 software and analyzed using descriptive (average - standard deviation percentage) and analytical (including Chi-square, t-test, and regression tests) tests.

\section{Results}

In this study, 3480 patients referred to hospitals in Hormozgan province with COVID-19 diagnosis have been evaluated. This number includes 1852 male patients $(53.20 \%)$ with a median age of $43.11 \pm 21.72$ and 1628 female patients $(46.80 \%)$ with a median age of $44.86 \pm 22.40$. The median age of men was lower than women significantly $(\mathrm{P}=0.02)$. The duration of hospitalization of male and female patients has been reported $2.64 \pm 4.14$ and $2.76 \pm 4.297$, respectively without a statistically significant relationship between the duration of hospitalization between different genders.

According to Figure 1, the most prevalent early symptoms in patients were headache (65.3\%), chest pain (64.3\%), and dizziness (63.6\%). 


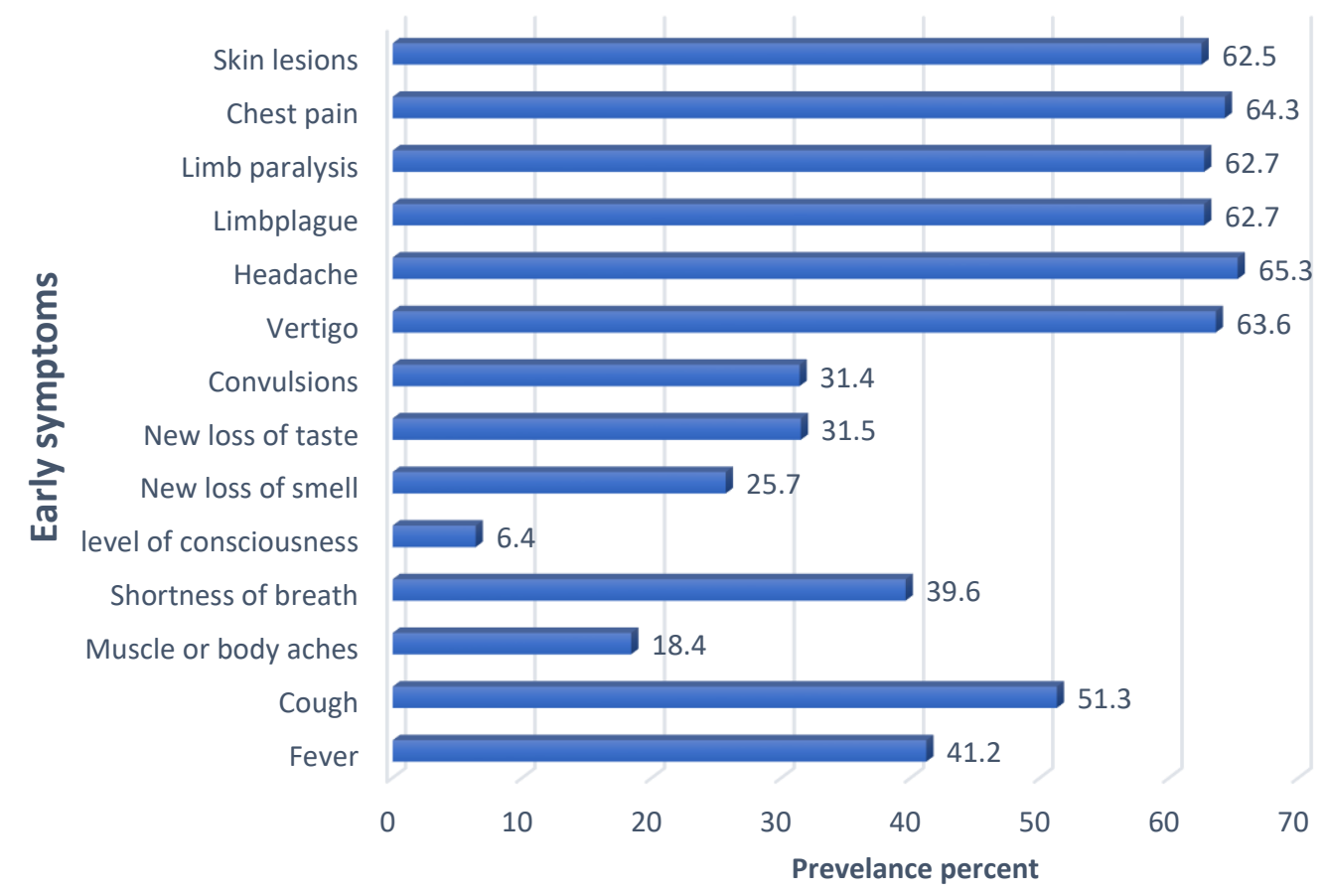

Figure 1. Early symptoms of patients referred to Hormozgan province hospitals

After examining the patients' gastrointestinal symptoms, it was found that the most common symptoms were vomiting (55.7\%) and diarrhea (55.6\%). Gastrointestinal symptoms are shown in Figure 2.

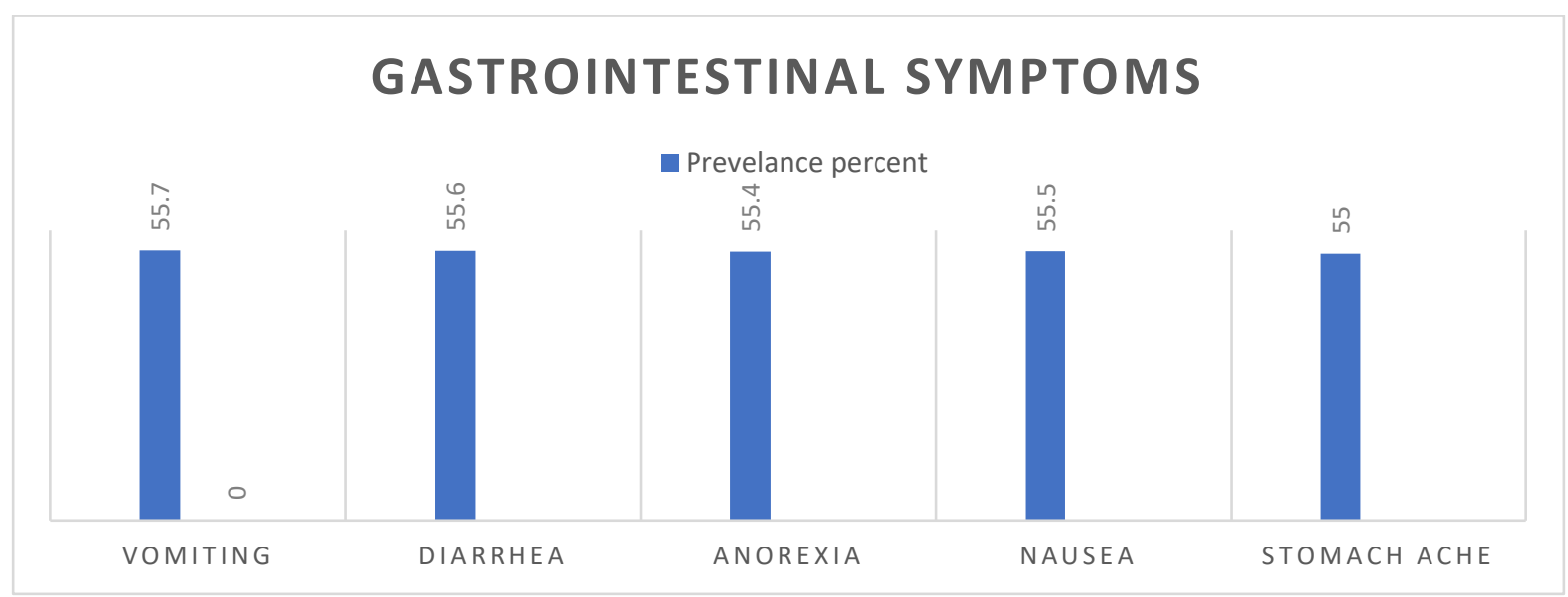


Figure 2. Gastrointestinal symptoms of patients referred to Hormozgan province hospitals

Table 1 shows the distribution of the variables between men and women. The mean age in men is lower than women and is statistically significant $(\mathrm{P}=0.020)$, liver disease, diabetes, hypertension, cardiovascular disease and asthma are different between men and women and are also statistically significant. ( $\mathrm{P}<0.05$ for all). The length of hospitalizations, cancer, HIV positive, immune deficiency, kidney, lung, and nervous system diseases showed no significant difference between men and women. Statistically, they were not significant $(\mathrm{P}>0.05$ for all $)$

Table 1. Distribution of quantitative and qualitative variables of patients with COVID-19

\begin{tabular}{|l|l|l|l|l|}
\hline Variable & Category/Scale & $\begin{array}{l}\text { Male1852(\%53.20) } \\
\text { Mean } \pm \text { SD or N (\%) }\end{array}$ & $\begin{array}{l}\text { Female 1628(\%46.80) } \\
\text { Mean } \pm \text { SD or N (\%) }\end{array}$ & P-value* \\
\hline Age & Years & $43.11 \pm 21.72$ & $44.86 \pm 22.40$ & 0.020 \\
\hline $\begin{array}{l}\text { Duration of } \\
\text { hospitalization }\end{array}$ & Day & $2.64 \pm 4.14$ & $2.76 \pm 4.297$ & 0.356 \\
\hline Cancer & Yes & $34(\% 1.80)$ & $33(\% 2.00)$ & 0.682 \\
\cline { 2 - 4 } & No & $1818(\% 98.20)$ & $1595(\% 98.00)$ & \\
\hline \multirow{2}{*}{ Liver disease } & Yes & $21(\% 1.10)$ & $4(\% .20)$ & \multirow{2}{*}{0.002} \\
\cline { 2 - 4 } & No & $1831(\% 98.90)$ & $1624(\% 99.80)$ & \\
\hline \multirow{2}{*}{ Diabetes } & Yes & $125(\% 6.70)$ & $171(\% 10.50)$ & $<0.001$ \\
\cline { 2 - 4 } & No & $1727(\% 93.30)$ & $1457(\% 89.50)$ & \\
\hline \multirow{2}{*}{$\begin{array}{l}\text { High blood } \\
\text { pressure }\end{array}$} & Yes & $19(\% 1.00)$ & $45(\% 2.80)$ & \\
\cline { 2 - 4 } & No & $1833(\% 99.00)$ & $1583(\% 97.20)$ & \\
\hline
\end{tabular}




\begin{tabular}{|c|c|c|c|c|}
\hline \multirow[t]{2}{*}{ HIV positive } & Yes & $1(\% 0.10)$ & $1(\% 0.10)$ & \multirow[t]{2}{*}{0.927} \\
\hline & No & $1851(\% 99.90)$ & $1627(\% 99.99)$ & \\
\hline \multirow{2}{*}{$\begin{array}{l}\text { Immune system } \\
\text { defects }\end{array}$} & Yes & $4(\% .20)$ & $7(\% .40)$ & \multirow[t]{2}{*}{0.262} \\
\hline & No & $1848(\% 99.80)$ & $1621(\% 99.60)$ & \\
\hline \multirow{2}{*}{$\begin{array}{l}\text { Cardiovascular } \\
\text { disease }\end{array}$} & Yes & $187(\% 10.10)$ & $204(\% 12.50)$ & \multirow[t]{2}{*}{0.023} \\
\hline & No & $1665(\% 89.90)$ & $1424(\% 87.50)$ & \\
\hline \multirow[t]{2}{*}{ kidney disease } & Yes & $50(\% 2.70)$ & $40(\% 2.50)$ & \multirow[t]{2}{*}{0.653} \\
\hline & No & $1802(\% 97.50)$ & $1588(\% 97.50)$ & \\
\hline \multirow[t]{2}{*}{ Asthma } & Yes & $70(\% 3.80)$ & $98(\% 6.00)$ & \multirow[t]{2}{*}{0.002} \\
\hline & $\mathrm{No}$ & 1782(\%96.20) & $1530(\% 94.00)$ & \\
\hline \multirow[t]{2}{*}{ Lung disease } & Yes & $52(\% 2.80)$ & $39(\% 2.40)$ & \multirow[t]{2}{*}{0.447} \\
\hline & No & $1800(\% 97.20)$ & $1589(\% 97.60)$ & \\
\hline \multirow{2}{*}{$\begin{array}{l}\text { Nervous system } \\
\text { disease }\end{array}$} & Yes & $21(\% 1.10)$ & $21(\% 1.30)$ & \multirow[t]{2}{*}{0.674} \\
\hline & No & 1831(\%98.90) & $1607(98.70)$ & \\
\hline
\end{tabular}

*P-values have been calculated based on Chi-Square or independent samples t-test.

Table 2 shows the association between Covid-19 hospitalization period and underlying diseases, HIV and pregnancy. Our result show that diabetic Covid-19 patients have a higher risk of prolonging hospitalization to one-seven days (OR $=1.445, \mathrm{CI} 95 \%=1.113-1.876, \mathrm{P}=0.006)$. In addition, Pregnany increased hospitalization period in Covid-19 patients to one-seven days ( $\mathrm{OR}=2.187,95 \%$ $\mathrm{CI}=1.245-3.842, \mathrm{P}=0.006)$. Covid-19 infected patients with cardio vascular disease had more risk of prolonging hospitalization to eight to 30 days. (OR $=$ $1.581,95 \% \mathrm{CI}=1.073-2.331, \mathrm{P}=0.021)$. Also our study showed that Covid-19 patients with kidney disease have more risk of prolonging hospitalization to eight to 30 days. $(\mathrm{OR}=2.889,95 \% \mathrm{CI}=1.535-5.435, \mathrm{P}=0.001)$. Besides, Cancer can increase hospitalization period in Covid-19 patients to more than 30 days. (OR $=$ 
26.475, 95\% CI $=7.687-91.185, \mathrm{p}<0.001)$. Concurent HIV and Covid-19 infection increases risk of hospitalization to more than 30 days $(\mathrm{OR}=3.136,95 \%$ $\mathrm{CI}=3.136-3.136, \mathrm{p}<0.001)$. Compared to patients with less than one day of hospitalization and patients with more than 30 days of hospitalization, people with cardiovascular disease have more risk of prolonging hospitalization. Concurent lung disease and Covid-19 infection increases risk of hospitalization to more than 30 days $(\mathrm{OR}=5.542,95 \% \mathrm{CI}=1.834-16.746, \mathrm{p}=0.002)$

Table2. Factors related to the length of hospitalization period of COVID-19 patients

\begin{tabular}{|c|c|c|c|c|c|c|c|c|c|}
\hline \multirow{2}{*}{$\begin{array}{l}\text { Hospitalizati } \\
\text { on period }\end{array}$} & \multicolumn{3}{|l|}{$1-7$} & \multicolumn{3}{|l|}{$8-30$} & \multicolumn{3}{|l|}{$30<$} \\
\hline & $\mathrm{OR}^{*}$ & $95 \% \mathrm{CI}$ & P-value & $\mathrm{OR}^{*}$ & $95 \% \mathrm{CI}$ & P-value & $\mathrm{OR}^{*}$ & $95 \% \mathrm{CI}$ & P-value \\
\hline \multicolumn{10}{|l|}{ Cancer } \\
\hline No & Ref & & 1.000 & Ref & - & 1.000 & Ref & - & 1.000 \\
\hline Yes & 0.884 & $0.516-1.513$ & 0.652 & 1.507 & $\begin{array}{l}0.665- \\
3.418\end{array}$ & 0.326 & 26.475 & $7.687-91.185$ & $\mathrm{p}<0.001$ \\
\hline \multicolumn{10}{|l|}{ Liver disease } \\
\hline No & Ref & - & 1.000 & Ref & - & 1.000 & Ref & - & 1.000 \\
\hline Yes & 2.079 & $0.879-4.921$ & 0.096 & 0.154 & $\begin{array}{l}0.003- \\
7.859\end{array}$ & 0.351 & 0.536 & $\begin{array}{l}0.000- \\
145.306\end{array}$ & 0.877 \\
\hline \multicolumn{10}{|l|}{ Diabetes } \\
\hline No & Ref & - & 1.000 & Ref & - & 1.000 & Ref & - & 1.000 \\
\hline Yes & 1.445 & $1.113-1.876$ & 0.006 & 1.223 & $\begin{array}{l}0.765- \\
1.955\end{array}$ & 0.401 & 0.249 & $0.013-4.786$ & 0.357 \\
\hline \multicolumn{10}{|l|}{$\begin{array}{l}\text { High blood } \\
\text { pressure }\end{array}$} \\
\hline No & Ref & - & 1.000 & Ref & - & 1.000 & Ref & - & 1.000 \\
\hline Yes & 0.799 & $0.466-1.369$ & 0.414 & 1.602 & $\begin{array}{l}0.724- \\
3.546\end{array}$ & 0.245 & 0.276 & $.000-189.651$ & 0.699 \\
\hline HIV positive & & & & & & & & & \\
\hline
\end{tabular}




\begin{tabular}{|c|c|c|c|c|c|c|c|c|c|}
\hline No & Ref & - & 1.000 & Ref & - & 1.000 & Ref & - & 1.000 \\
\hline Yes & 160 & $0.000-0.001$ & 0.998 & $\begin{array}{l}1141.5 \\
84\end{array}$ & $0.000-.001$ & 0.999 & 3.136 & $3.136-3.136$ & $\mathrm{p}<0.001$ \\
\hline \multicolumn{10}{|c|}{$\begin{array}{l}\text { Immune } \\
\text { system } \\
\text { defects }\end{array}$} \\
\hline No & Ref & - & 1.000 & Ref & - & 1.000 & Ref & - & 1.000 \\
\hline Yes & 0.438 & $0.103-1.870$ & 0.265 & 1.091 & $\begin{array}{l}0.159- \\
7.494\end{array}$ & 0.930 & 0.250 & $\begin{array}{l}1.443- \\
434.832\end{array}$ & 0.781 \\
\hline \multicolumn{10}{|c|}{ Pregnancy } \\
\hline No & Ref & - & 1.000 & Ref & - & 1.000 & Ref & - & 1.000 \\
\hline Yes & 2.187 & $1.245-3.842$ & 0.006 & 1.457 & $\begin{array}{l}0.490- \\
4.328\end{array}$ & 0.498 & 0.312 & $\begin{array}{l}1.781- \\
547.434\end{array}$ & 0.850 \\
\hline \multicolumn{10}{|c|}{$\begin{array}{l}\text { Cardiovascul } \\
\text { ar disease }\end{array}$} \\
\hline No & Ref & - & 1.000 & Ref & - & 1.000 & Ref & - & 1.000 \\
\hline Yes & 1.173 & $0.930-1.478$ & 0.178 & 1.581 & $\begin{array}{l}1.073- \\
2.331\end{array}$ & 0.021 & 5.542 & $1.834-16.746$ & 0.002 \\
\hline \multicolumn{10}{|c|}{$\begin{array}{l}\text { kidney } \\
\text { disease }\end{array}$} \\
\hline No & Ref & - & 1.000 & Ref & - & 1.000 & Ref & - & 1.000 \\
\hline Yes & 1.291 & $0.804-2.074$ & 0.291 & 2.889 & $\begin{array}{l}1.535- \\
5.435\end{array}$ & 0.001 & 0.320 & $0.002-42.406$ & 0.648 \\
\hline \multicolumn{10}{|c|}{ Asthma } \\
\hline No & Ref & - & 1.000 & Ref & - & 1.000 & Ref & - & 1.000 \\
\hline Yes & 0.939 & $0.679-1.298$ & 0.703 & 0.755 & $\begin{array}{l}0.385- \\
1.481\end{array}$ & 0.414 & 0.272 & $0.005-15.786$ & 0.530 \\
\hline \multicolumn{10}{|c|}{ Lung disease } \\
\hline No & Ref & - & 1.000 & Ref & - & 1.000 & Ref & - & 1.000 \\
\hline Yes & 1.044 & $0.674-1.618$ & 0.846 & 0.546 & $\begin{array}{l}0.191- \\
1.555\end{array}$ & 0.257 & 8.818 & $2.120-36.673$ & 0.003 \\
\hline \multicolumn{10}{|c|}{$\begin{array}{l}\text { Nervous } \\
\text { disease }\end{array}$} \\
\hline No & Ref & - & 1.000 & Ref & - & 1.000 & Ref & - & 1.000 \\
\hline
\end{tabular}




\begin{tabular}{|l|l|l|l|l|l|l|l|l|l|}
\hline Yes & 1.141 & $0.605-2.151$ & 0.685 & 0.971 & $\begin{array}{l}0.284- \\
3.324\end{array}$ & 0.962 & 0.247 & $\begin{array}{l}3.071- \\
198.735\end{array}$ & 0.808 \\
\hline
\end{tabular}

* Multinomial logistic regression was used with Hospitalization less than one day as the reference group; the baseline model included Cancer, Liver disease, Diabetes, High blood pressure, HIV positive, Immune system defects, Cardiovascular disease, Pregnancy, kidney disease, Asthma, Lung Disease, Nervous disease

\section{Discussion}

The Covid-19 disease severity depends on the interaction between the virus and the immune system. Virus-related factors including mutations, and the number of viruses exposed. An individual's immune system is also affected by genetics (e.g. HLA gene), age, gender, nutritional status, homeostasis in the immune system, nervous system, endocrine system, and physical condition. All of these factors contribute to an increased risk of an individual's infection, duration, severity, and recurrence of the disease. Due to the increasing need for covid-19 clinical areas (17), this study was conducted in the Hormozgan province, to analyze factors affecting COVID-19 patients hospitalization period.

The results of the study showed that gastrointestinal symptoms such as vomiting (55.7\%), diarrhea (55.6\%), nausea (55.5\%), and abdominal pain (55\%) are the most common symptoms among patients, which was inconsistent with other studies. In a meta-analysis study published by Tian et al(18), it was reported that $17.6 \%$ of patients with COVID-19 had gastrointestinal symptoms such as anorexia (26.8\%), diarrhea (12.5\%), nausea and vomiting (10\%), and abdominal pain $(9 \%)$. The most common symptoms of this disease, which have been reported in several articles, are fever higher than 38 degrees (78\%), cough (76\%), fatigue and muscle pain (44\%), shortness of breath (55\%), headache (8\%), bleeding (5\%), and diarrhea (3\%)(19-22).

In a study conducted by Erika et al., ten patients infected with COVID-19 initially presented gastrointestinal symptoms such as abdominal pain, nausea, and 
vomiting. The results indicated that in addition to gastrointestinal symptoms, nine of the patients had mild respiratory symptoms and fever before hospital admission (23). In recent studies, fever and respiratory distress prevalence in Covid-19 patients reported $80.2 \%$ and $23.4 \%$ respectively (24). These results are somewhat inconsistent with the results of our study as $39.6 \%$ of people complained of respiratory distress and also $4.2 \%$ of patients with fever symptoms.

The symptoms of COVID-19 appear after an incubation period routinely from 2-14 days (25) and the period from the onset of the disease to the death is 14 days on average. Furthermore, this period depends on factors such as the patient's age, immune system status, and underlying diseases (19). The results of the present study showed that cancer, HIV-positive and cardiovascular diseases, as chronic lung diseases can increase the hospitalization period of patients to more than 30 days.

A review article by Thomas et al., conducted in Australia, reported that the patient's hospitalization rate in the intensive care unit was about 5\% (26). In our study, $8.6 \%$ of the patients were hospitalized in the intensive care unit, which is inconsistent with the Thomas study. Besides, Shaoqing et al, reported that more than half of hospitalized patients needed intensive care unit stay(27).

Severe COVID-19 infection leads to severe inflammation, viral pneumonia, and different pulmonary and respiratory problems including acute respiratory syndrome (ARDS), which can eventually lead to death (28-31). In the present study, $39.6 \%$ of patients complained of respiratory distress. Also, $4.8 \%$ of patients with asthma and $2.6 \%$ of them had lung problems, which increases the death rate.

Conclusion: The death rate of patients in our study was $6.6 \%$. Although Hormozgan province was categorized in the red zone in terms of COVID-19 spread during this study but had a clearance rate of $96.4 \%$, all of which were in 
good general condition. This shows the acceptable and valuable performance of health services personnel in this province. The results of this study also showed that the hospitalization period of HIV-positive patients and patients with cardiovascular and pulmonary diseases is much longer than other people, which imposes many human and financial costs on the country's health care system. Therefore, to maintain individual health and help improve the critical condition of the virus, it is better to develop and apply stricter protocols to prevent further outbreaks of the disease and check underlying diseases of people suspected to have Covid-19. These results can improve health care system planning and improving medical services presented to covid-19 patients.

\section{Ethical considerations}

The authors declare that the investigations were carried out following the rules of the Declaration of Helsinki of 1975. The study protocol was approved by ethics committee of Hormozgan University of Medical Sciences with IR.HUMS.REC.1400.029 code.

\section{Acknowledgment}

The authors of this article would like to express our sincere gratitude to the health care system personnel of Hormozgan province as well as all the people whose assistance was a milestone in the completion of this research.

\section{Sponsors}

This article has no sponsorship.

\section{Contribution of authors}

All authors met the recommendations of the International Committee of Medical Journal Publishers.

\section{Conflict of interest}


The authors hereby state that there is no conflict of interest in the present study.

\section{References}

1. Wang L, Wang Y, Ye D, Liu Q. A review of the 2019 Novel Coronavirus (COVID-19) based on current evidence. Inter J Antimicrob Agents. Press; 2020.

2. $\mathrm{Xu} \mathrm{X,} \mathrm{Chen} \mathrm{P,} \mathrm{Wang} \mathrm{J,} \mathrm{Feng} \mathrm{J,} \mathrm{Zhou} \mathrm{H,} \mathrm{Li} \mathrm{X,} \mathrm{et} \mathrm{al.} \mathrm{Evolution} \mathrm{of} \mathrm{the} \mathrm{novel} \mathrm{coronavirus} \mathrm{from} \mathrm{the}$ ongoing Wuhan outbreak and modeling of its spike protein for risk of human transmission. Science China Life Sciences. 2020;63(3):457-60.

3. Ganji A, Gh M, Khaki M, Ghazavi A. A Review on Immunopathogenesis, Molecular Biology and Clinical Aspects of the 2019 Novel Coronavirus (COVID-19). Journal of Arak University of Medical Sciences (JAMS). 2020;23(1):8-21.

4. Chan JF-W, To KK-W, Tse H, Jin D-Y, Yuen K-Y. Interspecies transmission and emergence of novel viruses: lessons from bats and birds. Trends in microbiology. 2013;21(10):544-55.

5. Sun J, He W-T, Wang L, Lai A, Ji X, Zhai X, et al. COVID-19: epidemiology, evolution, and crossdisciplinary perspectives. Trends in molecular medicine. 2020;26(5):483-95.

6. Zhao C, Bai Y, Wang C, Zhong Y, Lu N, Tian L, et al. Risk factors related to the severity of COVID19 in Wuhan. International journal of medical sciences. 2021;18(1):120.

7. Yang $\mathrm{Y}, \mathrm{Lu} \mathrm{Q}$, Liu $\mathrm{M}$, Wang $\mathrm{Y}$, Zhang $\mathrm{A}$, Jalali $\mathrm{N}$, et al. Epidemiological and clinical features of the 2019 novel coronavirus outbreak in China. MedRxiv. 2020.

8. Bai Y, Yao L, Wei T, Tian F, Jin D-Y, Chen L, et al. Presumed asymptomatic carrier transmission of COVID-19. Jama. 2020;323(14):1406-7.

9. Yanez ND, Weiss NS, Romand J-A, Treggiari MM. COVID-19 mortality risk for older men and women. BMC Public Health. 2020;20(1):1-7.

10. Boccia S, Ricciardi W, loannidis JP. What other countries can learn from Italy during the COVID19 pandemic. JAMA internal medicine. 2020;180(7):927-8.

11. Lai C-C, Liu YH, Wang C-Y, Wang Y-H, Hsueh S-C, Yen M-Y, et al. Asymptomatic carrier state, acute respiratory disease, and pneumonia due to severe acute respiratory syndrome coronavirus 2 (SARS-CoV-2): Facts and myths. Journal of Microbiology, Immunology and Infection. 2020;53(3):40412.

12. Baud D, Qi X, Nielsen-Saines K, Musso D, Pomar L, Favre G. Real estimates of mortality following COVID-19 infection. The Lancet infectious diseases. 2020;20(7):773.

13. Filatov A, Sharma P, Hindi F, Espinosa PS. Neurological complications of coronavirus disease (COVID-19): encephalopathy. Cureus. 2020;12(3).

14. Ye M, Ren Y, Lv T. Encephalitis as a clinical manifestation of COVID-19. Brain, behavior, and immunity. 2020.

15. Hemilä H. Vitamin C intake and susceptibility to pneumonia. The Pediatric infectious disease journal. 1997;16(9):836-7.

16. Nonnecke B, McGill J, Ridpath J, Sacco R, Lippolis J, Reinhardt T. Acute phase response elicited by experimental bovine diarrhea virus (BVDV) infection is associated with decreased vitamin $D$ and $E$ status of vitamin-replete preruminant calves. Journal of dairy science. 2014;97(9):5566-79.

17. Bonalumi G, di Mauro M, Garatti A, Barili F, Gerosa G, Parolari A, et al. The COVID-19 outbreak and its impact on hospitals in Italy: the model of cardiac surgery. Oxford University Press; 2020.

18. Tian Y, Rong L, Nian W, He Y. gastrointestinal features in COVID-19 and the possibility of faecal transmission. Alimentary pharmacology \& therapeutics. 2020;51(9):843-51.

19. Wang W, Tang J, Wei F. Updated understanding of the outbreak of 2019 novel coronavirus (2019-nCoV) in Wuhan, China. Journal of medical virology. 2020;92(4):441-7.

20. Huang C, Wang Y, Li X, Ren L, Zhao J, Hu Y, et al. Clinical features of patients infected with 2019 novel coronavirus in Wuhan, China. The lancet. 2020;395(10223):497-506. 
21. Ren L-L, Wang Y-M, Wu Z-Q, Xiang Z-C, Guo L, Xu T, et al. Identification of a novel coronavirus causing severe pneumonia in human: a descriptive study. Chinese medical journal. 2020.

22. Carlos WG, Dela Cruz CS, Cao B, Pasnick S, Jamil S. COVID-19 disease due to SARS-CoV-2 (novel coronavirus). American Journal of Respiratory and Critical Care Medicine. 2020;201(4):P7-P8.

23. Poggiali E, Ramos PM, Bastoni D, Vercelli A, Magnacavallo A. Abdominal pain: a real challenge in novel COVID-19 infection. European journal of case reports in internal medicine. 2020;7(4).

24. Atalla E, Zhang R, Shehadeh F, Mylona EK, Tsikala-Vafea M, Kalagara S, et al. Clinical Presentation, Course, and Risk Factors Associated with Mortality in a Severe Outbreak of COVID-19 in Rhode Island, USA, April-June 2020. Pathogens. 2021;10(1):8.

25. Lauer SA, Grantz KH, Bi Q, Jones FK, Zheng Q, Meredith HR, et al. The incubation period of coronavirus disease 2019 (COVID-19) from publicly reported confirmed cases: estimation and application. Annals of internal medicine. 2020;172(9):577-82.

26. Thomas P, Baldwin C, Bissett B, Boden I, Gosselink R, Granger CL, et al. Physiotherapy management for COVID-19 in the acute hospital setting: clinical practice recommendations. Journal of Physiotherapy. 2020;66(2):73-82.

27. Lei S, Jiang F, Su W, Chen C, Chen J, Mei W, et al. Clinical characteristics and outcomes of patients undergoing surgeries during the incubation period of COVID-19 infection. EClinicalMedicine. 2020;21:100331.

28. Wu X, Nethery RC, Sabath BM, Braun D, Dominici F. Exposure to air pollution and COVID-19 mortality in the United States. MedRxiv. 2020.

29. Madarsara TJ, Kudakan NA, Yari S, Saeidabadi H. Assessing respiratory exposure to harmful evaporations in a manufacturing company. Asian Pacific Journal of Environment and Cancer. 2019;2(1):55-8.

30. Conticini E, Frediani B, Caro D. Can atmospheric pollution be considered a co-factor in extremely high level of SARS-CoV-2 lethality in Northern Italy? Environmental pollution. 2020;261:114465.

31. Andrée BPJ. Incidence of COVID-19 and connections with air pollution exposure: evidence from the Netherlands: The World Bank; 2020. 